\title{
Physico-chemical Parameterization and Determination of Effect of Tributaries on Enhancement of Pollutants in Bagmati River
}

\author{
Mandira Pradhananga Adhikari*, Madhav Raj Neupane, Madan Kafle \\ Central Department of Chemistry, Tribhuvan University, Kirtipur, Nepal \\ *CorrespondingE-mail:mandira43@hotmail.com \\ (Received: Sept. 18, 2019; Revised: Dec. 21, 2019 \& Accepted: Dec. 22, 2019)
}

\begin{abstract}
Water quality parameterization is a great concern because chemical contaminants and microbiological impurities including pathogenic bacteria may pose a health risk and unfit for its domestic use. Alkalinity, $\mathrm{pH}$, conductivity, chlorine demand, turbidity, and ammonia were measured to characterize the water quality of the Bagmati River. The effect of tributaries on Bagmati River was determined by sampling water from five different sites such as Pashupati (B-1), Shankhamul (B-2), Kupondol (B-1), Balkhu (B-4), and Jalbinayek (B-5) sites. The water samples B-2, B-3, B-4 and B-5 were less turbid but black in color while water sample $\mathrm{B}-1$ was more turbid but grey in color. The $\mathrm{pH}$ of water samples ranged from 6.7 to 7.3. The alkalinity, conductivity and chlorine demand were $60 \mathrm{ppm}, 95.7 \mu \mathrm{s}$ and, $5.44 \mathrm{ppm}$, respectively for B-1 sample and increased almost continuously from B-2 to B-5 sample. The alkalinity was $360 \mathrm{ppm}$, conductivity was 862 $\mu \mathrm{s}$ and chlorine demand was $23.7 \mathrm{ppm}$ for the last sample (B-5). The concentration of ammonia in the B-1 sample was only $0.0625 \mathrm{ppm}$ whereas it was $3.32 \mathrm{ppm}$ in the B-5 sample. The enhancement of chlorine demand and concentration of ammonia attributed that tributary and local effluent loaded extremely high levels of pollutants into the Bagmati River which might include pathogenic microorganisms. The random chance of some parameters like $\mathrm{pH}$, conductivity, ammonia, turbidity along the Bagmati River indicates the impacts of different tributaries on Bagmati River. The chorine demand showed a positive correlation with conductivity, alkalinity and ammonia while the negative correlation with turbidity. This revealed that the conductive alkaline pollutants consumed more chlorine than colloidal particles. From the study it is considered that the Bagmati River water contains natural as well as anthropogenic pollutants which is extremely hazardous not only to the people using river water but also for the living organism rely on the river.
\end{abstract}

Keywords: Alkalinity, chlorine demand, river water, turbidity, water pollution.

\section{Introduction}

The Bagmati originates from the Shivapuri Hills and flows through the Kathmandu valley. It is enormous important culturally, historically, biologically, and geologically. It is one of the holy rivers of Hindu. The river passes by the holy Pashupatinath and many other culturally important small temples. Culturally and historically, there are no alternatives to river water for the people in Kathmandu and other places of Nepal. People take bath, take water in their hands for paying gods and homage to their ancestors and bring small quantities of water to their home for use in rituals. It provides habitat and food for many living organisms. In addition, some people living near the bank are still using Bagmati River water for bathing, washing vegetables, utensils and clothing, in agriculture, industry and irrigation [1-3].

Such an immense important Bagmati River is suffering from an enormously high level of pollutants [4]. Many residents in Kathmandu valley are discharging untreated sewage, personal garbage and industrial waste into the river. The degradation of water quality and ecology of Bagmati River threaten not only human, but also living organisms rely on the river. The consumption of contaminated water causes a variety of water-borne diseases like cholera, dysentery, diarrhea, typhoid etc $[1,2,5]$. WHO estimates that about 3.4 million people die every year as a result of water- 
related diseases in developing countries [6]. In Nepal, many children up to 4 years die from water-borne diseases $[7,8]$. Although numerous campaigns were conducted to clean the Bagmati River, the stinking smell and blackish color of the Bagmati River water still increasing. This indicates that the determination of source of pollutants and the measurement of pollutants level along the Bagmati River is decidedly important to rectify the problem and implement the action effectively. The measurement of pollutant levels of water after mixing the tributaries will be the one step to rectify the role of tributaries on Bagmati River water pollution.

Water quality can be characterized by physicochemically and biologically [9]. Some of the commonly used Physico-chemical parameters are $\mathrm{pH}$, alkalinity, conductivity, ammonia, turbidity, dissolved oxygen (DO), biological oxygen demand (BOD), chemical oxygen demand (COD) etc. The measurement and comparison of these parameters with water quality standards can determine the quality and usability of water. High $\mathrm{pH}$ of river water is not suitable for life whereas low $\mathrm{pH}$ is especially harmful to immature fish and insects and also responsible for corrosion [5]. The highly alkaline water is usually unpalatable [10-12]. Conductivity relates to the salinity (total dissolved salt) and total dissolved solids, both of which affect water quality and aquatic life [11]. The decomposition of organic waste matter, gas exchange with the atmosphere, forest fires, animal and human waste and nitrogen fixation processes are the natural sources of ammonia. Ammonia is an important nutrient for plants and algae that reside in river water. However, the elevated concentration of ammonia is toxic to aquatic life. The concentrations ranging from 0.53 to $22.8 \mathrm{mg} / \mathrm{L}$ are toxic to freshwater organisms [9].

\section{Materials and Methods}

Samples were collected from five different sampling sites along the Bagmati River in September. This is the last month of the rainy season. Therefore, water level and velocity of water flow were high during the sampling time. The sampling sites were selected to determine the effect of the tributaries on the enhancement of the pollutant level including pathogen in the Bagmati River. The pretreated plastic bottles were used to collect samples from about 1 feet depth in each sampling site. The samples were collected randomly on different days. Therefore, the temporal variation of the water quality parameter of Bagmati river water was not considered in this study. The temperature and $\mathrm{pH}$ of water samples were measured directly on the spot using thermometer and $\mathrm{pH}$ meter (CE, pH600), respectively. The collected samples were brought into the laboratory and stored in a cool place and analyzed as soon as possible. Each sample was analyzed at least three times for each parameter.

Physico-chemical parameters were analyzed by using the standard method and using the instrument. The alkalinity, hardness were determined by titrimetric methods. Chlorine demand is measured by implementing the starch-iodine method. The concentration of ammonia was determined by the using Phenate method. The turbidity and conductivity of water samples were measured using Nephelometer and conductivity meter, respectively.

\section{Results and Discussion}

The present study was focused to measure the water quality parameter along the river to determine the effect of tributaries on the enhancement of contaminants on the Bagmati River inside the Kathmandu valley. As shown in Figure 1, water flows from Pashupati, Shankhmul, Kupondol, Balkhu sites to the Jalbinayak site. Along with the flow of water, it collects water from the Manahara, Dhobikhola, Bishnumati, and Balkhukhola rivers. The sampling covered about 12 kilometers length of the Bagmati River ranging from Pashupati to Jalbinayak. The sampling sites ( 5 sites) were selected in such a way that the effect of tributaries on the water quality of the Bagmati River could be determined. The sampling sites of Bagmati River were represented by the black spot in the Figure 1 . The water samples were represented as B-1, B-2, B-3, B-4 and B-5 for Pashupati, Shankhamul, Kupondol, Balkhu and Jalbinayak water samples respectively. The B-1 was considering as the water sample before loading pollutants from the tributaries of Kathmandu valley. The samples B-2, B-3, B-4 and B-5 determine the effects of Monohara, Dhobikhola, Bishnumati and Balkhukhola rivers on Bagmati River, respectively. Three samples were collected from B-1 and B-2 at different times. The analytical results showed the almost same value for different parameters. Therefore, the influence of time on the water quality parameter of Bagmati River water was not considered in this study. The samples were collected randomly at different 
sampling sites on different days.

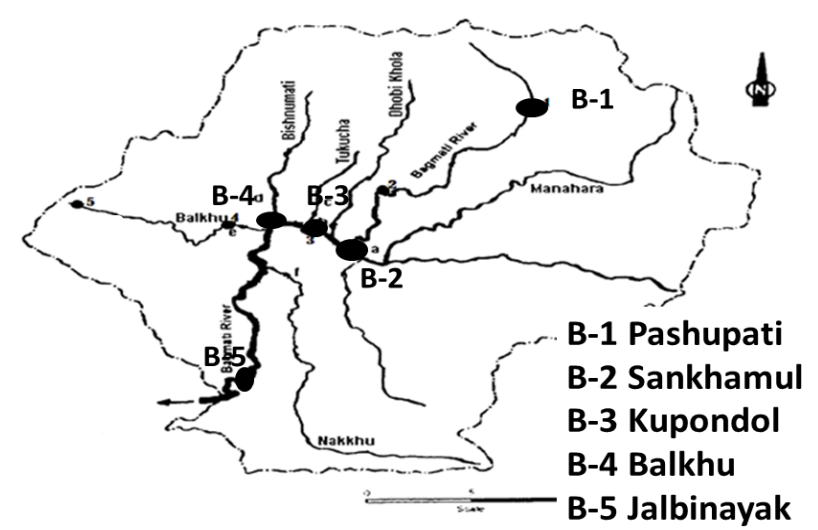

Figure1: Sampling sites of Bagmati River

\section{Physico-chemical parameterizations of river water sample}

The physical parameters such as temperature, color, $\mathrm{pH}$, and conductivity of five different samples were shown in Table 1 . Temperature was $19{ }^{\circ} \mathrm{C}$ in the case of B-1, B-2, and B-3 samples, and it was $18{ }^{\circ} \mathrm{C}$ in the case of B-4 and B-5. Some of the water quality parameters are influenced by the temperature of the water. High temperature decreases the oxygen level in the water which is favorable for the growth of bacteria at the anaerobic condition. This may enhance the chlorine demand. Similarly, the temperature also effects on physical properties such as $\mathrm{pH}$, conductivity, alkalinity etc. [6]. In this study, the samples were collected randomly from different observation sites. The observed temperatures of all samples were almost equal. Therefore it was considered that all samples had a similar environmental condition and the temperature difference had a negligible effect on the measured parameters of the samples. The color of water indicates the quality of water. It is greatly influenced by the suspended and dissolved particles as well as ambient conditions in which water is present. From the color of water, the physical, chemical and bacteriological conditions can be determined. The color of water sample the B-1 was grey in color while all other samples were black (Table 1) although the color of the B-3 sample was greyish black. The black color of river water is an indication of the presence of anthropogenic pollutants.

Bagmati River water flows continuously along with the sampling sites from B-1, to B-2, B-3, B-4 and
Table 1: Physical parameterization of water samples

\begin{tabular}{|c|c|c|c|c|}
\hline Water sample & $\begin{array}{c}\text { Temperature } \\
\left({ }^{\circ} \mathbf{C}\right)\end{array}$ & Color & $\mathbf{p H}$ & $\begin{array}{c}\text { Conductiv } \\
\text { isty } \\
(\boldsymbol{\mu} \text { S/cm })\end{array}$ \\
\hline B-1 & 19 & Grey & 7.3 & 95.7 \\
\hline B-2 & 19 & Black & 7.5 & 522 \\
\hline B-3 & 19 & Greyish Black & 7.1 & 582 \\
\hline B-4 & 18 & Black & 6.9 & 507 \\
\hline B-5 & 18 & Black & 6.7 & 862 \\
\hline
\end{tabular}

B-5. During its flow it collects water from different tributaries, hence, the water quality of Bagmati River water is influenced by the water quality of tributaries. Figure 2 shows photographs of water samples. The photograph shows that the B-1 sample was turbid and purely grey in color but the other samples were appeared black, dirty and unhealthy in nature. Figure 2 shows that the color and transparency were different for the different water samples. The sample B-2 was transparent and black in color. The sample B-3 was more turbid and black color was less pronounced as compared to sample B-2. Similarly sample B-4 appeared to be transparent but suspended particles were clearly observed in this sample. The sample B-5 was blackish in color. The photograph showed that B-1 sample mostly contains fine particles of clay and the sample B-3 contains clay particles with pollutants. However, other samples might contain pollutants such

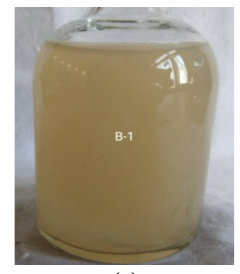

(a)

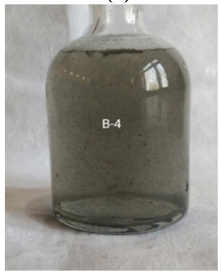

(d)

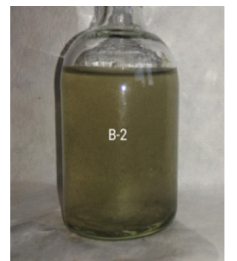

(b)

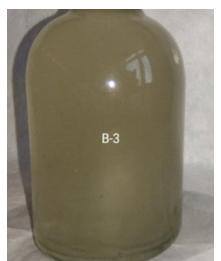

(c)

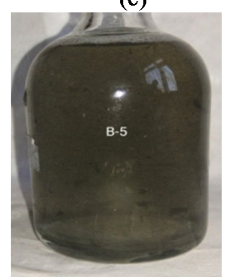

(e)
Figure 2: Photograph of water sample of (a) Pashupati ( $B$ 1), (b) Shankhamul (B-2), (c) Kupondol (B-3), (d) Balkhu $(B-4)$, and (e) Jalbinayak (B-5).

as dissolved organic matter, decaying sewage, nasty debris, etc.rather than clay particles [9]. The variation of color and transparency of sample water from upstream (Pashupati) to downstream (Jalbinayak) 
revealed that there was a great influence of tributaries on water quality parameters of Bagmati River.

The concentration of hydrogen ion $\left[\mathrm{H}^{+}\right]$in water is represented by $\mathrm{pH}$. The water with a low $\mathrm{pH}(<6.5)$ could be soft and corrosive while water with a high $\mathrm{pH}(>8.5)$ could be hard and corrosive in nature $[13,14]$. The $\mathrm{pH}$ of different water samples was tabulated in Table 1. The $\mathrm{pH}$ was ranged from 6.7 to 7.5 which falls within the range of natural water $(6.5$ to 8.5) [14]. The samples B-4 and B-5 were slightly acidic while other samples were slightly basic in nature. The $\mathrm{pH}$ revealed that water samples might contain weak electrolytes. Conductivity is related to the concentration of ions present in the water. The observed conductivity was $95.7,522,582,507$ and $862 \mu \mathrm{S} / \mathrm{cm}$ for the samples B-1, B-2, B-3, B-4 and the $\mathrm{B}-5$, respectively. The highest conductivity was observed in the case of B-5.The conductivity of water samples (B-2, B-3 and B-4) were five times and B-5 sample was almost nine times higher than that of B-1 samples. The drastic enhancement of conductivity attributed that the tributaries and/or local outlet loaded conducting pollutants in the Bagmati River.

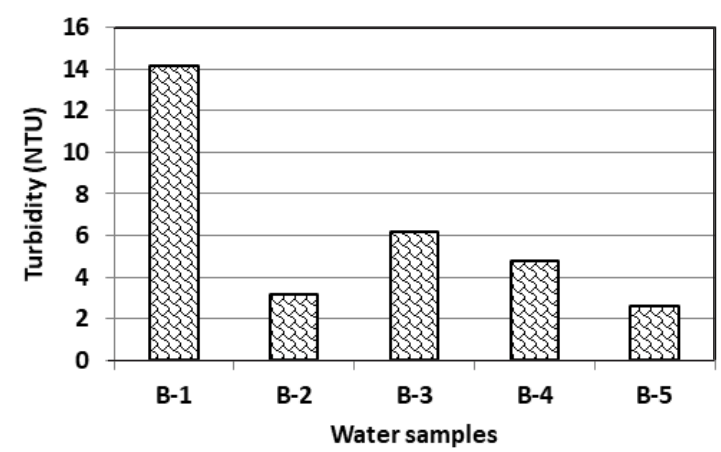

Figure 3: Turbidity of different water samples of Bagmati River

Turbidity is another important parameter that indicates the presence of insoluble particulate matter. Turbidity in natural water is caused by clay, silt, industrial wastes, organic matter, sewage, phytoplankton and other microscopic organisms. Excessive turbidity in river water is harmful to fish and aquatic animals however, it is suitable for food and shelter for pathogens which enhances the growth of pathogens [15]. The turbidity was 14.2, 3.2, 6.2, 4.48 and 2.64 NTU for sample B-1, B-2, B-3, B-4 and B-5, respectively (Figure $3)$. The maximum turbidity was observed in the case of a water sample from the Pashupati site (B-
1) i.e., before mixing of tributaries of Kathmandu valley. The measured turbidity of different sample water was comparable to the transparency revealed by the photograph (Figure 2). The photograph shows that the water samples B-2, B-4 and B-5 were more transparent that the water samples B-1 and B-3. The data attributed that the dark polluted water samples contains soluble pollutants whereas grey water samples contain insoluble suspended particles. From the results, it is considered that the less polluted grey water contains clay, silt etc. but polluted black water contain soluble conductive pollutants especially B-5.

Alkalinity protects water to become acidic. Hence, it is important for fish and aquatic life. The $\mathrm{pH}$ of the water will change when the buffering capacity of water is decreased. Water with low levels of alkalinity $(<155 \mathrm{ppm})$ has the low buffering capacity, hence, is more likely to be corrosive. The alkalinity of natural water is determined by dissolving the soil, limestone or dolomite minerals in the water $[12,14]$. Figure 4 shows that the alkalinity of water samples B-1 was low (50 ppm) but that of B-5 was more than 7 times higher (360 ppm). It was also found that alkalinity was increased continuously down flow from B-1 to B-5 sampling sites. Alkalinity mainly determines the concentration of carbonate, bicarbonate and hydroxyl ion in water. The alkalinity of the water sample reveals that water sample B-1 contains a less amount of carbonate and bicarbonate ions whereas concentrations of these ions were increased continuously by the tributaries in other samples. The alkalinity observed in this study was lower than that reported by previous studies (875 ppm [16] and 494 ppm [4]). The sample was collected in September. During this time the water level and flow velocity of Bagmati River were high. The lower value of alkalinity in this study may be due to the dilution of river water by continuous rainfall or due to the presence of anthropogenic pollutants rather than natural soil and minerals.

Ammonia gas is extremely soluble in water. It is found either as ammonium hydroxide or ammonium ion in the water. When the $\mathrm{pH}$ of the water is less than 7 the ammonia is present as the ammonium ion and as the $\mathrm{pH}$ of the water is higher than 7 it is present as the ammonium hydroxide [10]. Whatever may be the form of the presence of ammonia in natural water is considered as indicative of sanitary pollution. Although, it is widely used and common in 


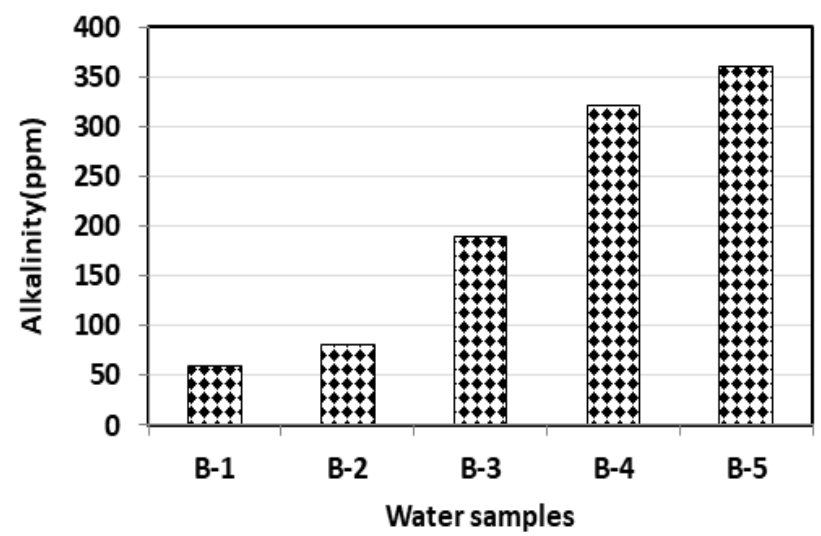

Figure 4: Alkalinity of different water samples of Bagmati River

our society, it can be both hazardous and caustic. It can block the transfer of oxygen in the gills of fish. The safe level of ammonia is between 0.02 and 0.4 in marine environments $[7,17]$. The concentration of ammonia observed for the different water samples was plotted in Figure 5. The ammonia concentration was only $0.0632 \mathrm{ppm}$ in the case of the B-1 sample which was within the limit $(0.2 \mathrm{ppm})$ for the surface water as recommended by WHO [17]. However, the concentration of ammonia was extremely high for the other samples. It was 2.3, 1.84, 1.63 and $3.32 \mathrm{ppm}$ for B-2, B-3, B-4 and B-5, respectively. The concentration of ammonia in B-2 and B-3 was very high as compared to that in the case of sample B-1but it was lower than that of the sample of B-2. The photograph (Figure 2) and turbidity (Figure 3 ) of water samples B-3 indicated that the sample contains clay particles in addition to another pollutant. The decrease in the concentration of ammonia in this sample may be due to the mixing of the tributaries such as Dhobikhola and Bishnumati containing less amount of municipal waste (sanitary pollution). Kafle (2016) reported that the Bagmati River water at Balkhu sites was more polluted than the Dhobikhola and Bishnumati river water [16]. Milner et.al. (2015) reported that the municipal waste and sewage entering the river drastically enhances the concentration of ammonia in Kathmandu valley especially near the Chovar (nearby B-5 sites of this study) [1]. The concentration of ammonia in the B-5 sample was highest and it was nearly two times that in the B-4 sample. It reveals that Blkhukhola loaded a high concentration of ammonia in the Bagmati River.
The difference between the amount of chlorine added and chlorine remaining (residual chlorine) after a certain time in the water sample is called chlorine demand. It depends on the chlorine dosage, contact time, temperature, $\mathrm{pH}$, nature, and amount of impurities in water. Chlorine demand was measured by maintaining a chlorine dose of $40 \mathrm{ppm}$, contact time of 35 minutes, the temperature at $18-19$ and $\mathrm{pH}$ of 6-7.

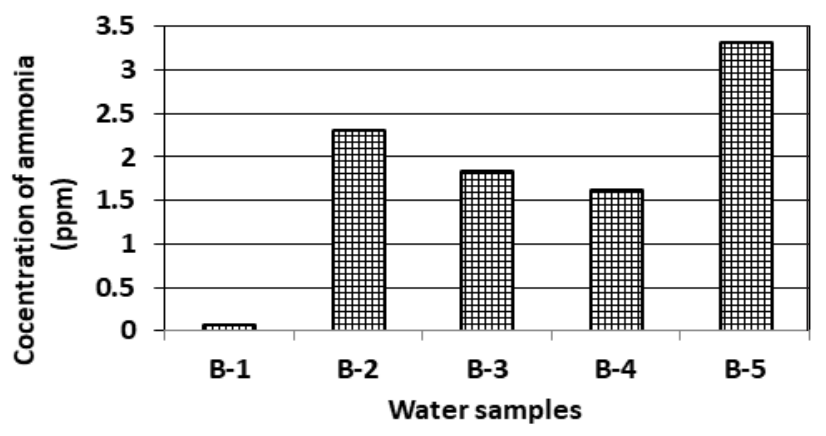

Figure 5: Ammonia concentration of different water samples

Figure 6 showed that the chlorine demand of B-1sample was low (5.44 ppm) and continuously increased from B-2 (11 ppm) to B-5 (23.7 ppm) samples. The chlorine demand attributes the presence of inorganic and organic contaminants with pathogenic microorganisms in the water $[4,13]$. Adhikari and Sah (2017) observed the chlorine demand as high as $12 \mathrm{ppm}, 20 \mathrm{ppm}$ and $22 \mathrm{ppm}$ for the Bagmati River (Pashupati site), Dhobikhola and Bishnumati, respectively. Increasing the chlorine demand along the Bagmati River revealed that tributaries and local effluent enhanced the pathogenic microorganism excessively in addition to chemical pollutants.

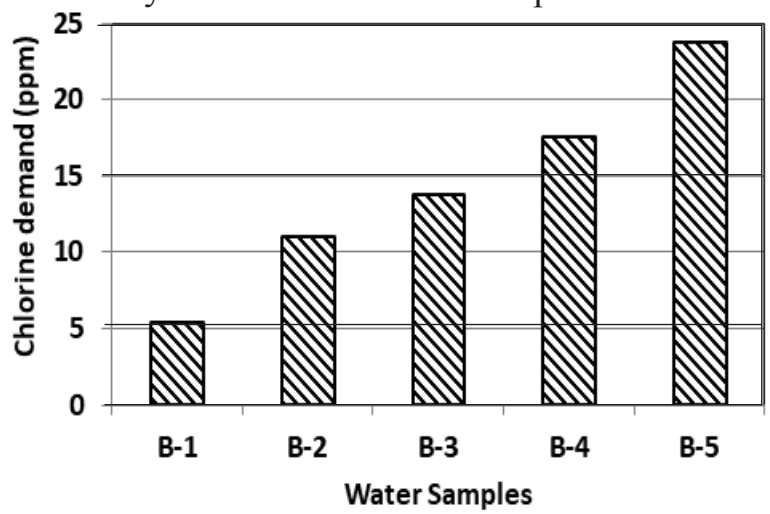

Figure 6: Chlorine demand of different water samples of the Bagmati River 


\section{Correlation curves}

Correlation is a statistical measure that indicates the extent to which two or more variables fluctuate together. A positive correlation indicates the extent to which those variables increase or decrease in parallel; a negative correlation indicates the extent to which one variable increases as the other decreases. The dependency of chlorine demand on different parameters such as ammonia, turbidity, alkalinity, and conductivity was shown below in Figure 7, 8, 9 and 10 respectively. Figure 7 shows the positive correlation between chlorine demand and concentration of ammonia on Bagmati River water. The correlation coefficient $\left(r^{2}=0.74\right)$ revealed the positive impact of ammonia concentration on chlorine demand for a given sample of water. The results attribute that the tributaries containing municipal waste loaded ammonia and pathogenic microorganism in the Bagmati River that excessively enhanced the chlorine demand.

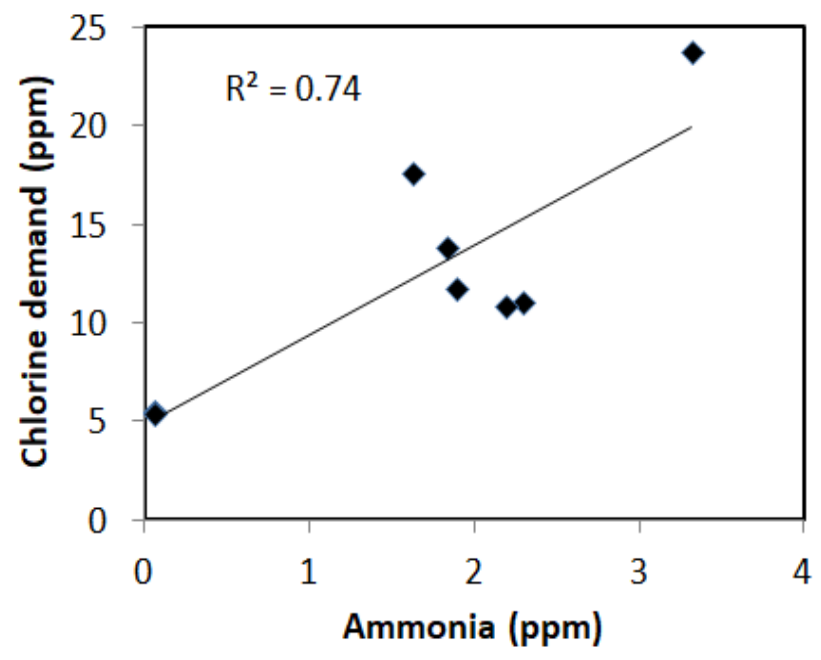

Figure 7: Correlation curve between chlorine demand and ammonia

Figure 8 shows the dependency of chlorine demand on the turbidity of different water samples in the Bagmati River. It evinced that there was a negative correlation between these variables i.e., the dependency of turbidity on chlorine demands for a given sample of Bagmati River was poor. The results attribute that the high consumption of chlorine by water sample was due to the presence of soluble impurities rather than the colloidal particles in the river water.
Figure 9 shows the dependency of chlorine demand on the alkalinity of different samples of water in the Bagmati River. There was a positive correlation $\left(r^{2}=0.86\right)$ between the variables and the correlation coefficient close to the proximity of unity.

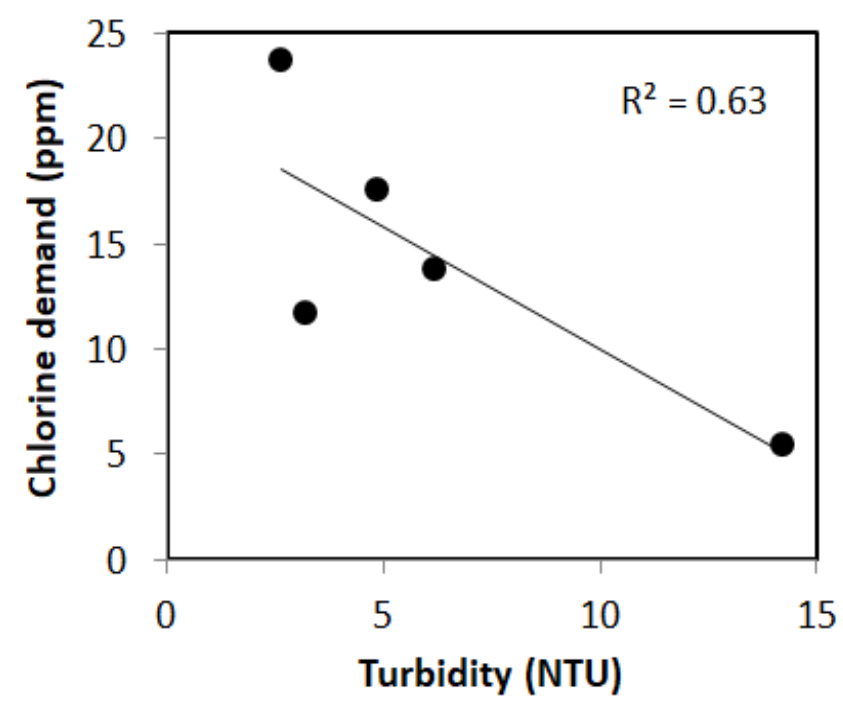

Figure 8: Correlation curve between chlorine demand and turbidity

Both these parameters were found to be increasing along the Bagmati River going down from Pashupati to Jalbinayak sites. It attributes that in addition to ammonia the alkalinity includes other pollutants that also consumed chlorine.

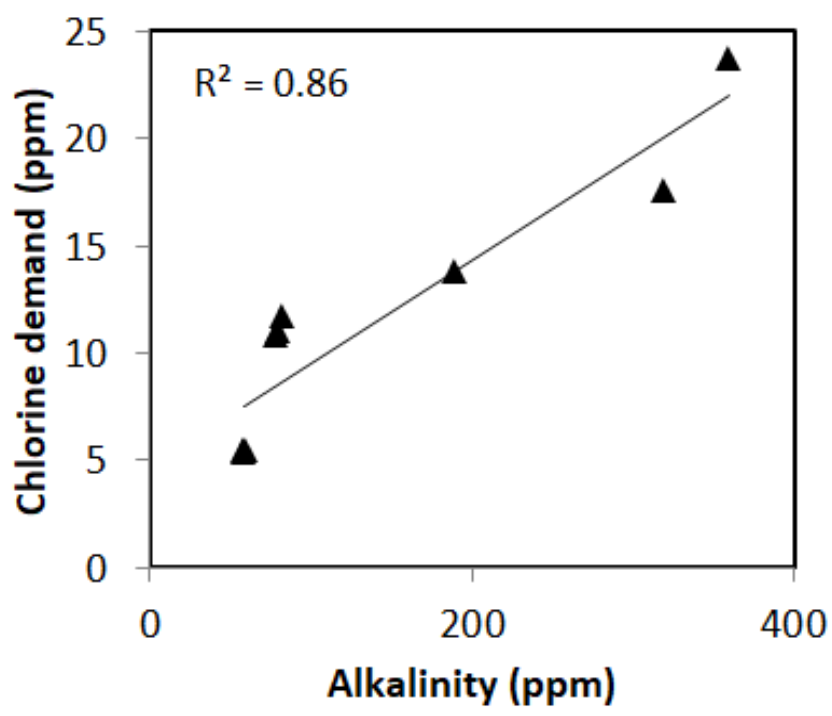

Figure 9: Correlation curve between chlorine demand and alkalinity 


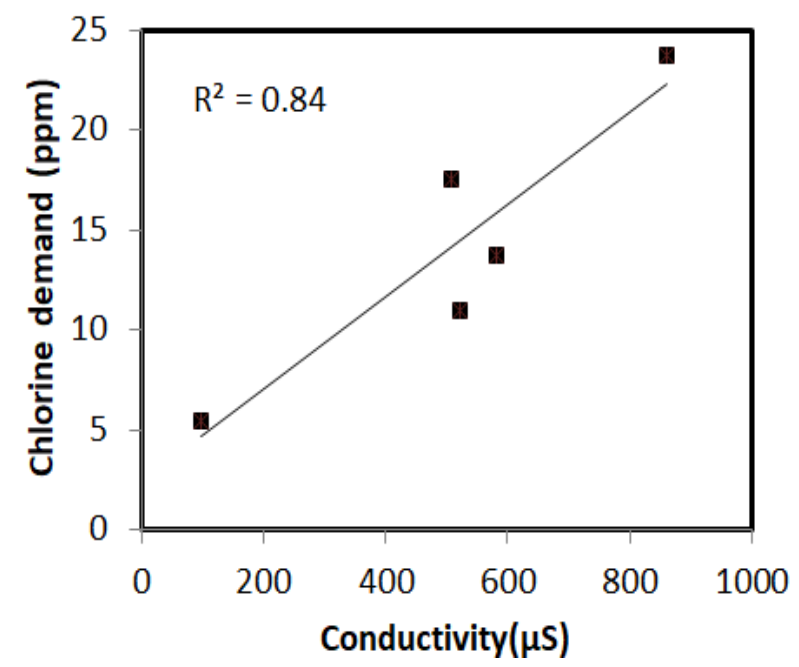

Figure 10: Correlation curve between chlorine demand and conductivity

Figure 10 shows the correlation between chlorine demand and conductivity of Bagmati River water. It showed that there was a positive correlation between the variables with a better correlation coefficient $\left(r^{2}=0.84\right)$ which was more close to the proximity of unity. Both these parameters were found to be increasing in all sampling sites going down from the Pashupati site to Jalbinayak. It inferred that in additions to pathogenic microorganism the conductive ions like ammonia, chlorides, sulfides, carbonates, bicarbonates present in the river water were responsible for high chlorine demand.

\section{Conclusion}

The water samples were collected from five different sites of the Bagmati River to understand the effect of tributaries on the Bagmati River water system. As expected all measured parameters such as $\mathrm{pH}$, alkalinity, conductivity, ammonia and chlorine demands were very low at the Pashupati site and very high at Jalbinayak site. The alkalinity and chlorine demand were continuously enhanced along the Bagmati River from Pashupati to Jalbinayak sites. The conductivity and ammonia were very low at Pashupati site and they were enhanced randomly along the downstream from Shankhamul to Jalbinayak. In addition to these parameters, $\mathrm{pH}$, color and turbidity of water samples attribute that the different tributaries had different impacts on the water quality of Bagmati River. All the measured parameters indicated that the B-5 sample contained an extremely high level of pollutants as compared to the B-1 sample. The extremely high concentration of ammonia and chlorine demand and color of the water samples attributed that effluent from Balkhukhola loaded extremely high levels of pathogenic microorganism in addition to chemical pollutants. The correlation curves attributed that the contribution of ammonia and alkalinity on chlorine demand was positive while that of turbidity was negative. It showed that the municipal waste containing soluble salt including ammonia consumed more chlorine than solid particles including clay, soil etc. Hence, it is considered that the tributaries are highly responsible for enhancement of precarious pollutants in river water, which is extremely hazardous for all living organisms, relies on the Bagmati River. A more detail study is necessary to understand the contribution of different tributaries in the enhancement of types and amount of pollutants in the Bagmati River.

\section{References}

1. C. Milner, H. Basnet, S. Gurung, R. Maharjan, T. Neupane, D. N. Shah, B. M. Shakya, R. Tachamo, R. D. Shah, and S. Vaidya, Bagmati River Expedition 2015: A baseline study along the length of the Bagmati River in Nepal to gather data on physical, chemical, and biological indicators of water quality and pollution; and document humanriver interaction, Nepal River Conservation Trust and Biosphere Association, Kathmandu, Nepal, 2015.

2. A. N. C Wolfe, Microbial contamination in the Kathmandu valley drinking water supply and Bagmati river. Master of Engineering Thesis. Civil and Environmental Engineering Department, Massachusetis Institute of Technology, USA, 2000.

3. M. Sagara and R. Lipscomb, Study of filtration for point-of-use drinking water treatment in Nepal, Veirginia Polytechnic Institute and State University, Falls Church, Virginia, 2003.

4. M. P. Adhikari and M. K. Sah, Chlorine demand and water pollutants of pond and river water, Journal of Nepal Chemical Society, 2017, 36, 3948.

5. M. S. Khadka, The groundwater quality situation in alluvial aquifers of the Kathmandu valley, Nepal, AGSO Journal of Australian Geology \& 
Geophysics, 1993, 14, 207-211.

6. WHO, Guidelines for Drinking Water Quality, $3^{\text {rd }}$ Ed, World Health Organization, 2004, Geneva.

7. S. Sharma, R. M. Bajracharya, B. K. Sitaula and J. Merz, Water quality in the central Himalaya, Current Science, 2005, 89(5), 774-786.

8. C. K. Sharma, Chemical pollution of the soil and groundwater in the Kingdom of Nepal, Ground Monit Manage, 1990, 173, 391-397.

9. M. O. Ben-Coker, Effect of Slaughter house discharge on Water Quality of Ikpoda River, Nigeria, Bioscience Technology, 2012, 2(1), 1-4.

10. M. K. Ladipo, V. O. Ajibola and S. J. Oniye, Seasonal variations in physicohemical properties of water in some selected locations of the Lagos lagoon, Science World Journal, 2011, 6(4), 5-11.

11. Ch. Leelavathi, U. K. Sainath, and A. K. Rabbni, Physicochemical characterization of ground water of Autonagar, Vijayawada, Krishna district, International Journal of Engineering Development and Research (IJEDR), 2016, 4(2), 1324-1328.

12. N. K. Koju, T. Prasai, S. Shrestha and P. Raut, Drinking water quality of Kathmandu valley, Nepal Journal of Science and Technology, 2014,
15(1), 115-120.

13. O. C. Modoi, C. Roba, Z. Torok and A. Ozunu, Environmental risks due to heavy metal pollution of water resulted from mining wastes in NW Romania, Environmental Engineering and Management Journal, 2014, 13(9), 2325-2336.

14. World Health Organization, International Standard for Drinking Water, 1999, 5, 3-6.

15. K. Cinque, M. A. Stevens, D. J. Roser, N. J. Ashbolt and R. Leeming, Assessing the health implications of turbidity and suspended particles in protected catchments, Water Science Technology, 2004, 50(1), 205-210.

16. M. Kafle, Chemical characterization of water from different sources at different places, M.Sc. Thesis, Central Department of Chemistry, Tribhuvan University, Nepal, 2016, 41-47.

17. World Health Organization "Guidelines for Drinking-Water Quality $4^{\text {th }}$ Ed, World Health Organization, 2011, 20 Avenue Appia, 1211 Geneva 27, Switzerland. 